\title{
Commentary: INSPIRE results? A critical appraisal of study end points
}

\author{
Konrad Hoetzenecker, MD, $\mathrm{PhD},{ }^{a}$ and Marcelo Cypel, MD, MSc ${ }^{\mathrm{b}}$
}

\footnotetext{
From the ${ }^{\mathrm{a}}$ Department of Thoracic Surgery, Medical University of Vienna, Vienna, Austria; and ${ }^{\mathrm{b}}$ Division of Thoracic Surgery, Toronto General Hospital, University of Toronto, Toronto, Ontario, Canada.

Disclosures: Cypel is cofounder of Perfusix Canada, XOR Labs Toronto and consultant for lung bioengineering. Hoetzenecker has nothing to disclose with regard to commercial support.

Received for publication June 10, 2019; accepted for publication June 12, 2019; available ahead of print July 26, 2019.

Address for reprints: Marcelo Cypel, MD, MSc, Division of Thoracic Surgery, Toronto General Hospital, 200 Elizabeth St, 9N969, Toronto, Ontario M5G 2C4, Canada (E-mail: marcelo.cypel@uhn.ca).

J Thorac Cardiovasc Surg 2019;158:1266-7

$0022-5223 / \$ 36.00$

Copyright $\subset 2019$ by The American Association for Thoracic Surgery

https://doi.org/10.1016/j.jtcvs.2019.06.034
}

We read with great interest the article by Loor and colleagues ${ }^{1}$ in this issue of the Journal, "Evaluation of the INSPIRE Trial and Its Implications for Lung Transplantation with Normothermic Portable Ex Vivo Lung Perfusion." This expert opinion aimed to summarize results of the INSPIRE trial and discuss their implications for the clinical routine. $^{2}$

The INSPIRE trial was a prospective, multicenter, randomized, controlled trial sponsored and designed by TransMedics, which aimed to compare preservation of standard donor lungs by the Organ Care System (OCS; TransMedics Inc, Andover, Mass) device to cold flush and static storage. The study reported comparable survivals, but with a lower incidence of primary graft dysfunction (PGD) within 72 hours in the OCS group, confirming results from a previously published randomized, controlled study by the Vienna group, which suggested the safety of ex vivo lung perfusion (EVLP) of standard lungs with a nonportable system. ${ }^{3}$ Both these trials, however, failed to show clinically relevant benefits to justify routine use of EVLP for lungs meeting standard criteria. In both studies, mechanical ventilation, intensive care unit stay, and hospital stay were similar between treatment and control arms, and short-term as well as long-term survivals were comparable. In fact, in the INSPIRE trial, 30-day survival was statically lower in the OCS arm $(94.7 \%)$ than in the cold static preservation arm $(100 \%)$; however, survivals at 1 year were exactly the same.

The results of the INSPIRE trial were controversially discussed in the community, mainly driven by weaknesses in the study protocol. A Food and Drug Administration executive summary published in May 2017 highlighted the most important confounders of the study. ${ }^{4}$ The main point of criticism was that the primary study end point had been changed during the study. Initially a composite primary end point of 30-day survival and PGD at 72 hours (t72) was defined. This was changed to 30-day survival and PGD within 72 hours (t0, t24, t48, or t72) at a time point

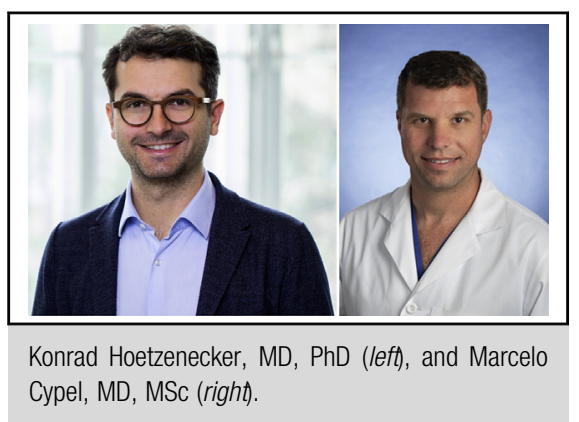

Central Message

Ex vivo lung perfusion was demonstrated to be safe in 2 randomized trials with standard criteria lungs; however, no clinically relevant benefits can be seen to justify its routine use in these donors.

See Article page 1259. when $64 \%$ of the enrollment had already been completed. It is well described that only PGD grades at later time points ( $\mathrm{t} 48$ and $\mathrm{t} 72$ ) correlate with survival. PGD grades at t0 hardly predict the further clinical course, and it is quite common that patients with mild bilateral infiltrations on arrival at the intensive care unit can be extubated within the next 2 days. In the INSPIRE trial, most of the differences in PGD were seen at t0 $(21 \%$ in the OCS arm vs $13 \%$ in the cold static preservation arm). This difference nearly equaled out until $\mathrm{t} 72(5 \%$ in the OCS arm vs 3.9\% in the cold static preservation arm).

In addition, chest x-ray evaluations and consequently PGD grades are highly susceptible to interobserver variability. We have previously shown that even trained thoracic radiologists only moderately agree in defining bilateral infiltrations in the modern era of lung transplantation, especially if radiographic changes are subtle. ${ }^{5}$ In case of a $\mathrm{PO}_{2}$ less than $200 \mathrm{~mm} \mathrm{Hg}$, a chest $\mathrm{x}$-ray diagnosis can make a difference between PGD grade 0 and PGD grade 3. We and others believe that alternative measurements-such as the ratio of $\mathrm{Po}_{2}$ to inspired oxygen fraction, compliance, length of mechanical ventilation or best forced expiratory volume in 1 second - might be more useful as markers of lung quality and need to be provided in future studies evaluating the effects of organ preservation strategies on primary organ function. 
The INSPIRE trial is an important study and represents one of the few prospective randomized trials in the field of lung transplantation. Although it did meet the intent of noninferiority, the results clearly demonstrate that similar clinical outcomes are achieved with current significantly "simpler" and "cheaper" cold static preservation.

In summary, cold static preservation continues to be the standard of care for preservation of donor lungs meeting standard criteria, whereas EVLP shows great promise for reevaluating and rehabilitating injured donor organs..$^{6-8}$ We believe, however, that EVLP for all lungs may come into play when ex vivo therapies demonstrate efficacy in decreasing graft immunogenicity and thus improving short- and long-term outcomes of lung transplantation. ${ }^{9,10}$

\section{References}

1. Loor G, Parulekar A, Smith M. Evaluation of the INSPIRE trial and its implications for lung transplantation with normothermic portable ex vivo lung perfusion. J Thorac Cardiovasc Surg. 2019;158:1259-63.

2. Warnecke G, Van Raemdonck D, Smith MA, Massard G, Kukreja J, Rea F, et al. Normothermic ex-vivo preservation with the portable Organ Care System Lung device for bilateral lung transplantation (INSPIRE): a randomised, open-label, non-inferiority, phase 3 study. Lancet Respir Med. 2018;6:357-67.
3. Slama A, Schillab L, Barta M, Benedek A, Mitterbauer A, Hoetzenecker K, et al. Standard donor lung procurement with normothermic ex vivo lung perfusion: a prospective randomized clinical trial. J Heart Lung Transpl. 2017;36:744-53.

4. Food and Drug Administration. Executive summary: Prepared for the May 17, 2017 meeting of the Gastroenterology and Urology Devices Panel. P160013 TransMedics, Inc, TransMedics OCSTM Lung System. Available at: https:// www.fda.gov/downloads/AdvisoryCommittees/CommitteesMeetingMaterials/ MedicalDevices/MedicalDevicesAdvisoryCommittee/Gastroenterology-Urology DevicesPanel/UCM558310.pdf. Accessed February 5, 2019.

5. Schwarz S, Muckenhuber M, Benazzo A, Beer L, Gittler F, Prosch H, et al. Interobserver variability impairs radiologic grading of primary graft dysfunction after lung transplantation. J Thorac Cardiovasc Surg. 2019;158:1266-7.

6. Cypel M, Yeung JC, Liu M, Anraku M, Chen F, Karolak W, et al. Normothermic ex vivo lung perfusion in clinical lung transplantation. N Engl J Med. 2011;364: 1431-40.

7. Machuca TN, Hsin MK, Ott HC, Chen M, Hwang DM, Cypel M, et al. Injuryspecific ex vivo treatment of the donor lung: pulmonary thrombolysis followed by successful lung transplantation. Am J Respir Crit Care Med. 2013;188: 878-80.

8. Galasso M, Feld JJ, Watanabe Y, Pipkin M, Summers C, Ali A, et al. Inactivating hepatitis $\mathrm{C}$ virus in donor lungs using light therapies during normothermic ex vivo lung perfusion. Nat Commun. 2019;10:481.

9. Cypel M, Liu M, Rubacha M, Yeung JC, Hirayama S, Anraku M, et al. Functional repair of human donor lungs by IL-10 gene therapy. Sci Transl Med. 2009;1:4ra9.

10. Figueiredo C, Carvalho Oliveira M, Chen-Wacker C, Jansson K, Höffler K Yuzefovych Y, et al. Immunoengineering of the vascular endothelium to silence MHC expression during normothermic ex vivo lung perfusion. Hum Gene Ther 2019;30:485-96 